\title{
A Comparison of EFL Fifth Graders' Vocabulary Acquisition through Skype Videoconferencing and Face-to-face Picture Book Storytelling
}

\author{
Hsing-Hui Chiu ${ }^{1}$, Chin-Fen Chen $^{2}$ \\ ${ }^{1}$ National Taiwan Normal University \\ ${ }^{2}$ National Taipei University of Education \\ Correspondence concerning this article should be addressed to Chin-Fen Chen, Department of Children \\ English Education, National Taipei University of Education, No.134, Sec. 2, Heping E. Rd., Da-an District, \\ Taipei City 106, Taiwan. E-mail: chinfen129@gmail.com
}

\begin{abstract}
This quasi-experimental study explores the relative efficacy of computer-mediated communication (CMC) and face-to-face picture book storytelling for promoting young EFL learners' English word acquisition. Thirty-two young EFL learners participated in a 40-minute story session in the two aforementioned modes. Receptive and productive word gains were assessed through immediate and delayed receptive vocabulary tests and productive story recall tests. To better explain how the CMC and face-to-face settings affected the participants' word gains, their involvement in the two types of storytelling settings was evaluated using an involvement load survey. The results show that the participants' task involvement was higher in the face-to-face setting than the CMC setting, which led to better word gains. Within each setting, high-involvement participants' word gain was better than that of their low-involvement counterparts. However, the difference between high-involvement and lowinvolvement participants was only manifest in the receptive word gains for the participants in the CMC setting, but not the productive word gains. These findings suggest that face-to-face storytelling might be the more effective setting when picture book storytelling is adopted to promote EFL young learners' word gains, especially for receptive word gains.
\end{abstract}

Keywords: Videoconferencing, Involvement Load Hypothesis, Young EFL Learners, Vocabulary Acquisition

\section{Introduction}

Videoconferencing, a form of computer-mediated communication (CMC), is a promising instructional medium that brings authentic language input and inter-cultural language exchange into a language classroom (Anderson \& Rourke, 2005; Morgan, 2013). It has also been commended for providing opportunities that are similar to face-to-face interaction for meaning negotiation between interlocutors and focus on form that facilitate second-language (L2) or foreign-language (FL) development (Akiyama, 2019; Bower \& Kawaguchi, 2011; Rassaei, 2017).

However, studies that explore the benefits and issues relevant to videoconferencing activities focus primarily on L2 or FL adult learners. Limited attention has been paid to implementing videoconferencing projects with elementary school learners, particularly in the EFL context. Amongst the existing studies that are conducted with elementary school FL learners, the focus is generally placed on the affective level, such as their attitude towards the technological support of language learning or attitude towards cross-cultural communication experiences (e.g., Cuestas, 2013; Ockert, 2015; Phillips, 2010; Tsukamoto, Nuspliger, \& Senzaki, 2009; Yu, 2018). The impact of the actual linguistic gains arising from videoconferencing activities is rarely explored in extant studies. 
As reported in Yu's study (2018), elementary school children's readiness and preparedness to engage in oneon-one videoconferencing activities pose difficulties for conducting such lessons or activities. Although learners' self-regulation and skills to operate technology individually require years of preparation and maturation, the potent potentiality of videoconferencing deserves our further exploration with elementary school children.

One possibility that is often utilized in videoconferencing sessions is to invite proficient English speakers to interact with the EFL learners. One such interaction event that is used frequently in the classroom for elementary FL learners is picture book storytelling-an important interaction activity for exposing FL learners to authentic language input in a formal education context. Specifically, storytelling exposes FL learners to rhetorical or discourse devices that are only employed by expert/native instructors (Lee, 2002), and it offers abundant, authentic, synchronous exchanges between expert/native speakers and FL learners (Lowenthal \& Dunlap, 2010).

Although storytelling through videoconferencing could be limited in its potency in co-presenting the narrator's gestures/facial expressions and the actual pictures/story at times (due to screen switching), it produces prompted feedback and more collaborative group interaction among all the group members than face-to-face contexts (Fahy, 2007). Importantly, like other digital distance learning materials, the content of digital storytelling can be recorded, thereby offering repeated listening and reviewing materials from expert/native speakers for FL learners-a valuable asset to FL instructors and learners.

Nevertheless, the aforementioned advantages of storytelling through videoconferencing are mainly examined and discussed in limited studies focusing on adult learners (e.g., Fahy, 2007). Videoconferencing studies on adult learners have shown that older and cognitively mature FL learners tend to direct their focal attention to meaning (such as exchanging ideas), rather than to meaning and form-which is the key for language acquisition (Lee, 2002). This finding suggests that videoconferencing does not always provide optimal scaffold in all facets of language development, at least as far as adult language learners are concerned. Whether this remains true for elementary FL learners warrants further research.

Accordingly, in spite of the increasing popularity of storytelling through videoconferencing in the elementary FL classroom, much remains unknown about how these learners allocate their attention to form and meaning in a picture book storytelling session, and how they interact with the participants in CMC videoconferencing and face-to-face settings, let alone empirical evidence validating elementary FL learners' linguistic gains in these two settings. Insights into the above issue not only provide empirical evidence on elementary school language learners' attention allocation during the storytelling process but also shed light on ways that teachers and learners can align for optimal learning outcomes in vocabulary learning, comprehension, or other linguistic aspects.

To shed light on the optimal picture book storytelling setting, this study sets out to compare the efficacy of picture book storytelling conducted in face-to-face classroom and videoconferencing contexts from the perspective of the Involvement Load Hypothesis (ILH; see 2.1 for more detail). Proponents of the ILH believe that higher involvement in a task will lead to better learning outcomes. It is hoped that the obtained data can add to our understanding of which storytelling setting (face-to-face versus videoconferencing) leads to higher involvement and whether higher involvement indeed results in better novel word acquisition as predicted by the ILH.

\section{Literature Review}

\section{Theoretical Framework: Involvement Load Hypothesis}

Malin (2010) argues that a reader of a story must engage the audience and create a "secondary world" that effectively invites the audience to visualize or imagine particular settings, and enact character roles in these settings. Without being engaged in the storytelling, the audience will not connect the story to their lives, and consequently they will not construct any mental imagery or meaning from it. Audiences who are not engaged or involved in seeing the storytelling events as a passive transmission of information and will not take interest 
in the action of the story-imagining and interpreting the story text and words. Accordingly, involvement is the key to the success of storytelling.

The Involvement Load Hypothesis (ILH) provides a motivational-cognitive construct framework to help us perceive and assess language learners' engagement with texts (Hulstijn \& Laufer, 2001). It conceptualizes the construct of involvement in terms of two cognitive components (i.e., need and search) and one motivational component (i.e., evaluation). To begin with, need is pertinent to learners' motivation or urge to engage with the text. Need is either moderate or strong depending on whether the motivation is self-imposed or extrinsic. Search and evaluation are relevant to the cognitive dimensions of involvement and are "contingent upon allocating attention to the form-meaning relationship" (Hulstijn \& Laufer, 2001, p. 543). Specifically, search refers to the attempt to find and/or construct the meaning of an unknown word or an L2 form to express a concept. It is thus either absent or present. Evaluation, on the other hand, is concerned with the decision and act to assess a word's meaning or 'goodness of fit' in context. Evaluation is strong if the comparison involves considering how additional words will combine with the target new word in a learner-generated (as opposed to given) context (Hulstijn \& Laufer \&, 2001). Evaluation is said to be moderate if the comparison only involves "recognizing differences between words" in a given context (as in a fill-in task with words provided)" or the comparison only encompasses "differences between several senses of $a$ word in a [given] context" (Laufer \& Hulstijn, 2001; p. 15).

The state of a learner's need, search, and evaluation varies in terms of prominence. Hulstijn and Laufer maintain that involvement in a task enhances the depth of input processing and degree of cognitive effort while encoding the input, with higher involvement load leading to better learning and retention of words. An extensive body of research has established that the evaluation of a learner's need, search, and evaluation helps predict whether a word can be learned and retained (e.g., Hu \& Nassaji, 2016; Zou, 2017). In this light, the ILH will serve as the theoretical and methodological tenet for the inquiries of this study, which set out to explore the correlation between learners' involvement and their word gains in the face-to-face and CMC settings.

While the studies mentioned above set out to explore the ILH in the context of L2 written vocabulary acquisition (where learning is mainly based on input from one modality) and provided positive evidence supporting the claims of the ILH, few of them have explored the ILH in the contexts of multimodal input such as videoconferencing picture book storytelling and face-to-face picture book storytelling.

\section{Videoconferencing on Foreign Language Learning}

Videoconferencing has been widely applied for educational purposes and language learning. A growing number of studies have acknowledged that during videoconferencing learners are able to receive authentic language input, produce output, and receive prompt feedback. Literature has also examined the extent to which videoconferencing contributes to learners' L2 and FL linguistic development.

First, learners gained more intercultural awareness through videoconferencing activities. Chen and Yang (2014) paired 15 Taiwanese seventh graders with Pakistani students. After participating in storytelling and crosscultural discussions, the pairs found themselves more confident when engaging in inter-cultural communication. Moreover, videoconferencing can promote collaborative learning strategies and enhance oral communication skills. Cuestas (2013) conducted interview sessions where 23 elementary students and an expert/native speaker discussed a prepared topic. The qualitative data suggested that the learners' increased peer scaffolding and motivation in speaking. Lim and Pyun (2019) paired Korean-learning U.S. university students with students from Korea for videoconferencing language learning tasks. The students in general made significant progress in their speaking and listening abilities. In addition, those students participating in the Korean-US study became motivated and confidant engaging in target language exchange. Phillips (2010) kept journal interview, and informal conversation notes and concluded that British students were motivated to speak the target language and engage in conversations when receiving videoconferencing instruction. In Ockert (2015), the Japanese-Australian elementary student pairs self-reported more desire to engage in FL learning activities after videoconferencing sessions. Finally, studies suggested that specific tasks via videoconferencing facilitate learners to focus on form. Akiyama (2019) explored Japanese FL adult learners in the US learning vocabulary through different modalities and concluded that videoconferencing, compared with text chat and images only, resulted in better vocabulary learning. 
Additionally, the issues and processes of designing videoconferencing activities in educational contexts and language learning were also explored. For instance, Andrew (2005) suggested in his review reports that effective videoconferencing design and learning should match the teacher's particular teaching style and the need to engage learners through effective discussions between and among learners and teachers. Echoing that, Acar (2007) cautioned that the design of videoconferencing activities should be interaction-oriented. Yu (2018) also suggested that during videoconferencing sessions, teachers should elicit discussions regarding the goal of the activity and the learners' language proficiency as well as their affective factors.

In reviewing relevant literature on videoconferencing, a limited scope was found to have investigated participants in elementary schools as compared with adult learners as shown in Table 1 . To fill the gap, the current study hopes to expand the scope by exploring fifth graders' novel word acquisition through a commonly used classroom practice - storytelling.

Table 1

Empirical Research on Videoconferencing

\begin{tabular}{|c|c|c|}
\hline Research & Participants & Major Findings \\
\hline Akiyama (2019) & University students & Participants scored higher in videoconferencing vocabulary learning \\
\hline Phillips (2010) & Elementary students & $\begin{array}{l}\text { Participants felt more confident speaking the target language and were } \\
\text { motivated to engage in videoconferencing sessions }\end{array}$ \\
\hline Chen \& Yang (2014) & $7^{\text {th }}$ grade students & Participants gained more cultural communicative competence \\
\hline Cuestas (2013) & $\begin{array}{l}11-12 \text { year old elementary } \\
\text { students }\end{array}$ & $\begin{array}{l}\text { Participants exerted more "peer-scaffolding" and "engagement" in speaking } \\
\text { activities }\end{array}$ \\
\hline Lim \& Pyun (2019) & University students & $\begin{array}{l}\text { Participants made significant progress in listening and speaking abilities } \\
\text { via videoconferencing }\end{array}$ \\
\hline Ockert (2015) & Elementary students & $\begin{array}{l}\text { Participants self-reported a stronger desire to engage in international } \\
\text { contexts and foreign language activities }\end{array}$ \\
\hline Rassaei (2017) & University students & $\begin{array}{l}\text { Oral corrective feedback via videoconferencing was found to be as effective } \\
\text { as face-to-face }\end{array}$ \\
\hline Souzanzan (2017) & Elementary students & $\begin{array}{l}\text { The experimental group's (via videoconferencing) speaking ability } \\
\text { outperformed the control group }\end{array}$ \\
\hline Yen, Hou \& Chang (2015) & University students & Participants improved their speaking and writing skills \\
\hline Yu (2018) & Fifth grade students & $\begin{array}{l}\text { Uneven participants performance was noted due to commitment, learning } \\
\text { attitude, personalities, and language proficiency }\end{array}$ \\
\hline
\end{tabular}

\section{Videoconferencing vs. face-to-face mode of picture book storytelling}

Storytelling research conducted with foreign language learners indicates that stories have the potential to harness the growth of learners' vocabulary (Kirsch, 2016; Lee, 2005; Yeung et al., 2016). The process of storytelling with elementary-level learners is an intricate process. It entails communicative interactions and tasks that are imposed upon learners for them to guess or infer unknown words from various teacher scaffolds and book illustrations (Kirsch, 2016). To this end, a teacher usually employs a plethora of techniques to promote learner engagement, interest in and understanding of the text, including, but not limited to, paraphrase, use of body actions or hand gestures, intensive eye-contact, prompting questions while reading the text, and cognitive tasks that require the audience to search for missing information, to name a few.

Although it is believed that videoconferencing contributes to L2 development by providing opportunities for authentic communication and drawing learners' attention to linguistic input, it is important to note that learners' attentional allocation strategies may be qualitatively different in the face-to-face and CMC settings (Kim, 2014). Specifically, in traditional classrooms where teachers are physically present with the learners, learners' attention to the teacher and the scaffolds used by the teacher during the picture book storytelling session is, in most cases, under the control of the learners. In a picture book storytelling session delivered through videoconferencing, teachers often have to switch the screens between the picture book content and themselves. In this case, what the learners should focus on, in most cases, controlled by the teacher, rather than the learners. In other words, the attentional orientation is mainly controlled by the learners in the face-to-face picture book storytelling setting and the teacher in the CMC setting. Which type of attention control would 
lead to deeper involvement in a picture book storytelling session is yet to be revealed. However, hitherto, we still do not know a lot about the relative efficacy of picture book storytelling in these two settings.

In light of this, the current study probes the efficacy of storytelling in the videoconferencing and face-to-face contexts with a focus on novel word learning. the Involvement Load Hypothesis is used as a framework to gauge learners' involvement or attention to various tasks in storytelling. Two questions are explored in the present study:

1. What is the relative efficacy of videoconference and face-to-face

2. storytelling in terms of their potency to promote the L2 word acquisition of fifth grade learners?

3. How does fifth grade learners' involvement, as assessed by their states for need, search, and evaluation, affect the relative efficacy of videoconferencing and face-to-face storytelling in promoting L2 word acquisition?

\section{Methodology}

\section{Participants}

Two classes of EFL fifth grade Chinese-speaking students (age: 12-13) in a public elementary school in Taipei participated in the study, a total of 32 students. All of them had evaluated their English performance in $4^{\text {th }}$ grade and were grouped into the same level of English classes. In other words, both classes of participants were comparable in terms of their English learning experiences and initial English proficiency. At the time of the study, there were no students in either class attending special education programs and no students had disabilities. Both of the classes were assigned randomly to be the CMC storytelling (i.e., videoconferencing) group and face-to-face storytelling group.

Furthermore, based on their scores from the self-reported task involvement survey (see 3.3 for more detail), the participants from each class were further subdivided into high-involvement group and a low-involvement group. The participants whose average mean score for each statement was above 2 or approximately 2 , were grouped into the high-involvement group, and the others were placed in the low-involvement group. The highinvolvement group is considered to be those who invested significant attentional resources, and the lowinvolvement group those, who did not, during the picture book storytelling session.

In addition to the two groups of participating students, an experienced English teacher with a master's degree and 20 years of teaching experience was invited to be the storyteller for the two classes. She presented the same story book to two classes with the same presentation style and the exact same inquiry questions.

\section{Picture Book and Target Words}

The picture book used in this study was Edwina: The Dinosaur Who Did Not Know She Was Extinct (Willems, 2006). The book was selected for its topic familiarity to the participants and relevance of content (student daily life), context (classroom, park, neighborhood streets), and age appropriateness (K-2), as validated by both the participants' regular native and non-native English teachers. Edwina is a loving dinosaur who bakes chocolatechip cookies for everyone and helps her neighbors. Everyone loves her except one smart little boy, Reginald, who is determined to prove to his classmates that dinosaurs are extinct. Six target words were chosen from the book to maintain the $6 \%$ unknown word density rate prescribed by Nation and Coady (1988). The target words were chosen for their importance in understanding the plots of the story. Those unknown words were also presented on pages with clear illustrations that could aid the participants' inferring process. The six target words were: Edwina, care, bake, except, extinct, protesting.

\section{Research Design and Instrument}

The present study employed a quasi-experimental design. All participants experienced a picture book storytelling session, with half of them taking place in a traditional face-to-face setting and half of them through a CMC (i.e., Skype-videoconferencing) setting. Regardless of the picture book setting they attended, all participants completed the following tasks: (1) a picture book storytelling session; (2) a self-reported task 
involvement survey; (3) three receptive vocabulary tests (i.e., a pretest, an immediate post-test, and a delayed post-test); and (4) two story recall tasks (i.e., immediate and delayed). The ensuing paragraphs will describe these above tasks in more detail.

\section{Picture Book Storytelling Session}

Both the face-to-face and CMC storytelling sessions took place in the participants' L2 (English), and the participants were encouraged to respond to the storyteller in the L2 (but were given the freedom to use their L1). One experienced EFL instructor was recruited as the storyteller for the study. This instructor had been teaching young EFL learners for more than 20 years, and importantly had been using picture books both in the face-to-face and CMC settings for many years. The EFL instructor ensured that the qualities of L2 use, emphasis of specific story events, interactive tasks, vocabulary focus, and time allocation could be maintained equally in both the face-to-face and CMC settings. The contents of the picture book were displayed to the participants via Keynote as the story was told.

During the traditional face-to-dace storytelling session, the storyteller narrated the stories with body languages, facial expressions, modulating voice, chants, and prompt questions accompanied with the presentation of the Keynote slides. Prompt questions were strategically used to enhance story comprehension and highlight target word meanings. Brief summary sessions were also administered using the method thinkpair-share to ensure all participants had equal opportunities to listen to their partners and produce the target words in contexts. It is important to note that a natural classroom is full of interactions and reactions between the instructor and students. Different classes could have different responses to a certain event. The storyteller ensured critical moves, such as narrating, stopping points for prompt questions, pair and group discussions, were taken into account in both settings. Despite the storyteller's efforts to maintain a similar narrating style in the CMC and face-to-face settings, the storyteller had to switch between the camera view (which highlighted the storyteller) and the digital image view (the picture book and animation) from time to time. Consequently, the participants in the CMC setting were not able to fully see the scaffolds from the storyteller's face or body movement when the screen was switched to the picture book. Despite this, the audio input from the storyteller in the CMC setting was unaffected. Generally speaking, the storyteller, who was also the English teacher for the two classes, was trying to process the instruction with the same moves, following the same sequence of teaching activities, and posing the same inquiry questions.

\section{Self-reported Task Involvement Survey}

The survey was designed to gauge the participants' involvement in tasks during the storytelling session. It is important to note that the participants' involvement load can be artificially manipulated/induced by a task (see Hulstijn \& Laufer, 2001), and that in this regard, the participants' involvement can only be indirectly inferred through the nature and demand of the task assigned to the participants. In this study, we felt that the participants' self-reflection or retrospection of their experience during the picture storytelling event would provide a more accurate picture of their actual involvement load. To this end, a task involvement load survey, which contained seven statements written in the participants' L1, was constructed (See Table 3, Section 4.1 for details).

In this survey, the participants were instructed to read and rate each statement based on the three components prescribed by Hulstijn and Laufer (2001):

1. Need $(\mathrm{N})$ : learners' perceived motivation or urge to engage with the text. This component was dichotomously assessed: either moderate (1: extrinsic motivation) or strong (2: intrinsic motivation)

2. Search (S): learners' actual attempt to find and/or construct the meaning of an unknown word or an L2 form to express a concept, which was also dichotomously assessed: either absent (0) or present (1)

3. Evaluation (E): learners' actual act to assess a word's meaning or 'goodness of fit' in context, which was gauged on a 3-point scale: absent (0), moderate (1) and strong (2)

After the experimental instruction, the researcher interviewed all of the participants about the seven statements, inquiring as to their experiences of vocabulary learning during the storytelling session. When the interview started, the participants were instructed to read through the statements on the survey, answering the researcher's questions and explained their responses toward each statement, which were rated respectively by means of Hulstijn and Laufer's rating method. 
Taking interviewing about the first statement as an example (see Table 3), the researcher would first ask the participant to read the statement, then answer whether he/she had had such an experience during the storytelling session. If he/she answered no, he/she would get zero points for the "Search" component. It implied that he/she had not applied the specific strategy during the storytelling session; thus, no more questions would be asked and the survey would proceed to the second statement. The participant would be rated zero for both "Need" and "Evaluate" for the first statement.

On the other hand, if the participant answered yes, he/she would be asked to give an example of his/her experience and he/she would get one point for the "Search" component. Then the researcher asked the participant “Did you do it out of your own interest or by the teacher's request?" If he/she answered doing it out of their own interest, then they got two points for the "Need" component, referring to his/her intrinsic motivation. If he/she did it by teachers' request, then they got one point for the "Need" component, which was encouraged outwardly. Lastly, the researcher asked the participant whether he/she had tried to apply the word to communicate with others in class. If their answer was no, they got zero points for the "Evaluation" component. If their answer was yes, they needed to give examples and tell how many times they used the word in context. If they applied the word for more than one time, they would obtain two points for the "Evaluation" component. The points they obtained based upon their responses toward the three components were then summed up for every participant's performance in the study. The highest total score a participant could get for each statement was five points and the lowest was zero. The higher points they obtained, the more involvement they were considered to have engaged in during the experimental instruction. The average performance of all the participants is presented in Table 3.

In the above spirit, the participants in this study were asked to rate seven involvement load statements in terms of need, search, and evaluation when coming across a novel word or phrase. A participant's involvement load is inferred through the sum of the need, search, and evaluation points they earned for the seven statements. The seven statements, which described various common acts that young FL learners may undertake/experience in a picture book storytelling events (e.g., using illustration to make sense of a novel word) in the participants' L1, were constructed based on a survey administered to several experienced EFL teachers who have been using picture books in their classes for more than ten years. The seven statements aimed at assessing the aggregate amount of involvement load the picture book storytelling task imposed on the participants. To ensure the participants' understanding of the statements and the reliability of their ratings of the statement, the wording of the statements was carefully written for the fifth graders and was validated by two educational psychologists. Additionally, the researcher provided oral explanations and examples for each statement before the participants started their rating.

Hulstijn and Laufer (2001) contend that the aggregate amount of need, search, and evaluation a task imposes on the learner positively determines the outcome of word learning and retention. Based on the participants' points for the survey, the participants in the CMC and face-to-face groups were further subdivided into two groups; the participants whose average mean score for each statement was above 2 were grouped into the high involvement group, and the others were into the low involvement group.

\section{Receptive Vocabulary Tests}

Three vocabulary tests (the pretest, the immediate posttest, and the delayed posttest) were administered to gauge the participants' receptive word gains. The three tests were identical in terms of format and all contained 16 items, including six target words and 10 distractors. The vocabulary pretest was used to ensure that all six target words were indeed novel to the participants prior to the picture book storytelling session. During the pretest, the words were visually presented and read aloud to the participants, who were told to circle the words. For each word circled, the participants were then asked to explain their knowledge of the words either in their L1 or L2. In other words, the recognition of word meaning was focused on and explored. The same procedure was repeated in both the immediate and delayed vocabulary posttest. The immediate posttests and delayed posttests contained the original pretest items but the presentation order in the two posttests was shuffled and hence different across the tests. An example of the pretest is presented in Table 2.

\section{Productive Vocabulary Test in the Form of Story Recall}

In addition to the aforementioned receptive vocabulary measures, all participants were asked to recollect and then retell the contents of the story using their L2 (English) twice: once immediately after the storytelling 
Table 2

An Example of the Receptive Vocabulary Pretest

\begin{tabular}{|c|c|c|c|}
\hline bake & protesting & smile & hair \\
\hline Edwina & happy & care & dinosaur \\
\hline grandmother & call & hair & listen \\
\hline
\end{tabular}

session and a second time four weeks after the storytelling session. This productive task was administered to determine the participants' ability to recall and produce the target vocabulary-words that were novel to the participants both in terms of (spoken) form and meaning prior to the study-in a sentential context. If the participants were capable of recalling and producing the target vocabulary, it would provide a strong case for their productive word gain and retention in the face-to-face and CMC settings. A point would be awarded when and if a word was pronounced intelligibly and in an adequate sentential context during their recall as verified by the storyteller (see Chen \& Han, 2010 for a similar design). Examples of a sentential context are given below:

- She bakes cookies for everybody.

- She is very kind.

- Dinosaurs are extinct.

- Everyone likes her except the little boy.

Moreover, since grammaticality is not an issue in the present study, the rating did not consider grammatical errors such as incorrect conjugation, parts of speech, or tense. Using the target word care, for example, one point would be awarded in all of the following scenarios below:

She doesn't care. / She no care. / She not care. / She is not care.

\section{Procedure}

All participants completed the following tasks in sequence: (1) a vocabulary pretest; (2) a picture book storytelling session; (3) an immediate story recall task; (4) an immediate vocabulary posttest, (5) a self-reported task involvement survey; (6) a delayed recall test; and (7) a delayed vocabulary posttest. To begin with, the vocabulary pretest, which took five to ten minutes for each participant to complete, was administered to the participants one week prior to the storytelling session. The picture book storytelling session lasted for 40 minutes. Immediately after the storytelling session, the participants were first asked to recall the story (using the L2), ${ }^{1}$ then complete the vocabulary posttest, which took about ten minutes to complete, and finally the selfreported task involvement survey, which took about five minutes to complete. The last step of data collection was the delayed story recall and delayed posttest, which were both conducted four 4 weeks after the storytelling session.

\section{Results}

\section{Self-reported Task Involvement Survey}

Results of the participants' self-reported involvement survey for the face-to-face and CMC settings in terms of their need to learn unfamiliar words, the way they searched for ways to learn those words, and how they evaluated different strategies of word learning are presented in Table 3.

\footnotetext{
1 The story recall/retell was administered prior to the immediate vocabulary posttest so that the vocabulary test items would not serve as a prompt and obscure the recall data.
} 
The seven statements describe seven frequent strategies the participants might utilize to understand and learn an unknown word/phrase during a picture book storytelling session. A participant's involvement during the session was determined based on the total sum of each participant's scores for all seven involvement statements. As noted earlier, the participants whose score for each statement was 2 or above, were grouped into the high involvement group, and the others went into the low involvement group. Table 3 displays the mean scores of the high and. low involvement groups in the face-to-face and CMC settings.

Table 3

Self-reported Task Involvement Survey Results

\begin{tabular}{|c|c|c|c|c|c|}
\hline No. & Involvement Statement & $F / H^{*}$ & F/L & $\mathbf{C} / \mathbf{H}$ & $\mathrm{C} / \mathrm{L}$ \\
\hline 1 & $\begin{array}{l}\text { I sought to know more about unfamiliar words/phrases and/or learn about their } \\
\text { meanings through studying relevant illustrations. }\end{array}$ & $3.00 * *$ & 3.00 & 1.71 & 3.00 \\
\hline 2 & $\begin{array}{l}\text { I sought to know more about unfamiliar words/phrases and/or learn about } \\
\text { their meanings through the teacher's facial expressions, body language, and/or } \\
\text { explanations. }\end{array}$ & 2.33 & 1.88 & 2.14 & 1.88 \\
\hline 3 & $\begin{array}{l}\text { I sought to know more about the unfamiliar words/phrases and/or learn about their } \\
\text { meanings through asking the teacher or my classmates. }\end{array}$ & 2.00 & 1.88 & 1.29 & 1.13 \\
\hline 4 & $\begin{array}{l}\text { I sought to know more about the unfamiliar words/phrases and/or learn about their } \\
\text { meanings through guessing. }\end{array}$ & 2.00 & 1.50 & 1.54 & 1.75 \\
\hline 5 & $\begin{array}{l}\text { I sought to know more about unfamiliar words/phrases and/or learn about their } \\
\text { meanings through mnemonic strategies. }\end{array}$ & 2.00 & 2.00 & 1.71 & 1.75 \\
\hline 6 & $\begin{array}{l}\text { I sought to know more about the unfamiliar words/phrases and/or learn about their } \\
\text { meanings through reading them out loud. }\end{array}$ & 3.00 & 1.13 & 2.14 & 0.38 \\
\hline 7 & $\begin{array}{l}\text { I sought to know more about the unfamiliar words/phrases and/or learn about their } \\
\text { meanings through listening to other student read aloud or comments.) }\end{array}$ & 3.00 & 1.88 & 3.00 & 1.50 \\
\hline & Mean total scores of the four sub-groups & 17.33 & 13.27 & 13.53 & 11.39 \\
\hline & Mean total scores of the two high groups & \multicolumn{2}{|c|}{15.30} & \multicolumn{2}{|c|}{12.46} \\
\hline
\end{tabular}

*Note. F/H stands for face-to-face and high involvement load group (N=9); F/L stands for face-to-face and low involvement load group $(\mathrm{N}=8)$; $\mathrm{C} / \mathrm{H}$ stands for $\mathrm{CMC}$ and high involvement load group (N=7); C/L stands for CMC and low involvement load group $(\mathrm{N}=8)$

**Note. This number stands for the mean score: the total score of statement one averaged by 9 (participants).

Overall, the participants assigned to the face-to-face setting appeared to show more involvement, as gleaned from the general score of all statements of the higher mean involvement groups' scores (Mean = 15.30), than that of their counterparts assigned to the CMC setting (Mean $=12.46$ ). Furthermore, the high-involvement participants in the face-to-face setting seemed to exert more mental effort in making sense of and learning about unknown words $($ Mean $=17.33$ ) than the high-involvement participants in the CMC setting (Mean = 13.53). A similar scenario was also seen for the low-involvement participants in the two settings; the lowinvolvement participants in the face-to-face setting (Mean = 13.27) also made more mental effort than their counterparts in the CMC setting (Mean =11.39). Although the low-involvement participants in the face-to-face setting's involvement rating (13.27) are nearly on par with the high-involvement group in the CMC setting (13.53), overall face-to-face storytelling setting seemed to lead to a higher involvement load.

Accordingly, it can be inferred that differential degrees of task involvement were perceived in the CMC and face-to-face storytelling settings; the task involvement was greater in the face-to-face setting than the CMC setting. Based on the results above, we can reasonably assume that the same tasks in the two different storytelling contexts induced differential involvement loads upon the participants.

\section{Receptive Vocabulary Tests}

Table 4 shows the mean scores of the three receptive vocabulary tests for each group. The mean pretest scores (0) indicated that the six target words were all novel to all participants. The results in both the immediate and delayed vocabulary posttests suggest that all of the participants could recognize more than half of the (six) target words. Notably, the participants listening to stories in the traditional face-to-face context recognized more words and retained them better than those listening to stories in the CMC setting, both in the immediate ( 4.5 vs. 3.75 words, respectively) and delayed posttests ( 4.22 vs. 2.87 words, respectively). In addition, the high 
involvement participants in both the CMC and face-to-face settings performed better than the low involvement participants, suggesting that higher involvement is the key to better word learning outcomes. One may notice a backslide in the participants' performance in the delayed test, probably due to memory attrition. Notwithstanding, the regression in the face-to-face setting is not manifest (4.5 vs. 4.22 words) in spite the time lapse (four weeks) between the immediate and delayed tests.

Table 4

Test Scores in the Immediate and Delayed Receptive Vocabulary Posttests

\begin{tabular}{|c|c|c|c|c|c|}
\hline \multirow{3}{*}{$\begin{array}{l}\text { Instructional Conditions } \\
\text { Face-to-face }_{(\mathrm{N}=17)}\end{array}$} & \multirow{3}{*}{$\begin{array}{c}\text { Involvement Load } \\
\operatorname{High}_{(\mathrm{N}=9)} \\
\operatorname{LoW}_{(\mathrm{N}=8)}\end{array}$} & \multicolumn{2}{|c|}{$\begin{array}{c}\text { Immediate Posttest } \\
\text { (mean) }\end{array}$} & \multicolumn{2}{|c|}{$\begin{array}{l}\text { Delayed Posttest } \\
\text { (mean) }\end{array}$} \\
\hline & & 4.88 & 45 & 4.56 & 422 \\
\hline & & 4.13 & & 3.88 & \\
\hline \multirow{2}{*}{$\mathrm{CMC}_{(\mathrm{N}=15)}$} & $\operatorname{High}_{(\mathrm{N}=7)}$ & 4 & \multirow{2}{*}{3.75} & 3.00 & \multirow{2}{*}{2.87} \\
\hline & Low $_{(\mathrm{N}=8)}$ & 3.5 & & 2.75 & \\
\hline
\end{tabular}

\section{Story Recall/Retell}

In the current study, the relative efficacy of a given storytelling session (e.g., face-to-face vs. CMC) for promoting productive word gain was inferred through between-group comparisons of the number of words learned and produced under a given setting. Between-group comparisons of the average number of words learned and produced by all participants under a given setting could shed light on the relative efficacy of a given storytelling session (e.g., face-to-face vs. CMC). ${ }^{2}$ The production of each (target) word is considered as an instance or type for 'a word for production; and the times each given word is produced in a sentence is token that instantiates that type in context. In the analysis of the participants' productive word gain, we considered both the type (i.e., number of target words being produced) and tokens (i.e., the times each target word being produced) under the face-to-face and CMC settings.

In terms of type, as seen in Table 5 below, the participants in the face-to-face setting generally outperformed their counterparts in the CMC setting both in the immediate and delayed story recall tests (4.5 words vs. 3 words, respectively). In particular, an average of five target words (out of six) were recalled and produced by the high-involvement participants in the face-to-face setting in both the immediate and delayed recall tests: Edwina, care, extinct, except, bake. Considering that all of the participants had zero knowledge of the six target words prior to the face-to-face picture book storytelling session, this word gain (acquiring productive knowledge of the five target words) can be considered quite a feat. Even the low-involvement participants in the face-toface setting were able to produce an average of four target words (Edwina, care, extinct, bake). On the other hand, the participants in the CMC setting recalled fewer words; only an average of three target words (Edwina, care, except) were recalled and produced by the participants in the CMC group, including both the high and lowinvolvement participants. Accordingly, the face-to-face setting seemed to lead to more target words being used in the participants' production (oral recall discourse) than the CMC setting.

Table 5

Target Word Tokens Recalled and Used by the Participants in the Immediate and Delayed Recall Tests

\begin{tabular}{lllc}
\hline \multirow{2}{*}{$\begin{array}{c}\text { Instructional } \\
\text { Conditions }\end{array}$} & \multicolumn{1}{c}{ Immediate Recall } & \multicolumn{2}{c}{ Target Words Retrieved From The Spoken Data } \\
\cline { 2 - 5 } F/H & Edwina, care, extinct, except, bake & Edwina, care, extinct, except, bake & 5 words \\
F/L & Edwina, care, except, bake & Edwina, care, except, bake & 4 words \\
C/H & Edwina, care, except & Edwina, care, except & 3 words \\
C/L & Edwina, care except & Edwina, care, except & 3 words \\
\hline
\end{tabular}

\footnotetext{
2 Fine-grained quantitative analysis is not the ideal analysis tool in the context of the current study due to the small number of audience members typically participating in a picture book storytelling session.
} 
In terms of tokens, as seen in Figure 1, although the three target words (Edwina, care, except) were produced by the participants in both the face-to-face and CMC settings, the token count for each word was higher in the face-to-face setting than the CMC setting in the immediate story recall test. In particular, the token count for the word Edwina produced by the participants listening to stories in the face-to-face setting $(92: 51+41)$ is three times as many as the token count produced by their counterparts in the CMC setting $(27: 12+15)$. In the same trend, the token count for the word care produced by the participants in the face-to-face setting $(23: 13+10)$ is 1.4 times higher than the token count produced by their counterparts in the CMC setting $(17: 11+6)$. The token count for the word except produced by the participants in the face-to-face setting $(10: 6+4)$ is, again, 5 times higher than the token count produced by their counterparts in the CMC setting $(2: 1+1)$.

\section{Figure 1}

Target word token count in the immediate recall test

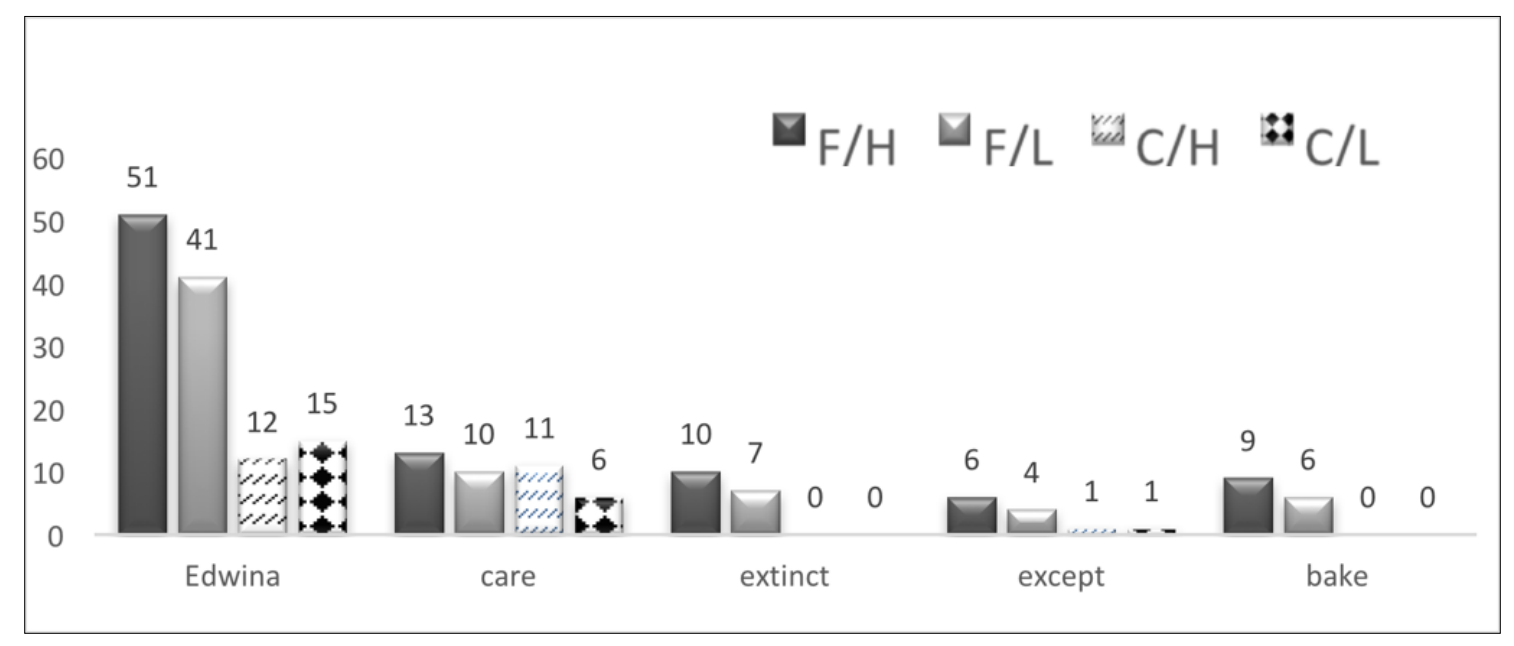

The above token count comparison does not just entail the difference in the number of times a word being produced in context. One may recall that all of the words were being produced (and hence embedded) in the sentential context. So, the token counts reported above also shed light on the discrepant differences in the length of oral discourse produced by the participants in the face-to-face and CMC settings. For instance, a token count of 17 entails seventeen sentences (that were embedded with a given target word) being produced. A higher vocabulary token count value is thus also indicative of longer discourse in the oral story recall task. Thus, the observation that the participants in the face-to-face setting have significantly higher token counts in the immediate story recall task also means that the participants in the face-to-face setting produced significantly longer oral discourse than their counterparts in the CMC setting.

The same scenario-the face-to-face storytelling being more effective in promoting productive word gainswas also evidenced in the delayed story recall test (four weeks after the storytelling session). As seen in Figure 2 below, irrespective of the picture book storytelling condition (CMC vs. face-to-face), the same words that were recalled by the participants in the immediate recall test were also retained and recalled by the participants in the delayed recall test. This finding is suggestive of the importance of recall-an act of production-in retaining novel vocabulary. Although the token counts significantly dropped in the delayed posttest, and hence were lower than the token counts in the immediate posttest probably due to the participants' memory attrition in the delayed story recall test, the pattern in the immediate story recall test was replicated in the delayed recall test. Specifically, the token count for the word Edwina produced by the participants listening to stories in the face-to-face setting $(48: 23+25)$ is, again, three times as many as the token count produced by their counterparts in the CMC setting $(15: 9+6)$. The token count for the word care produced by the participants in the face-to-face setting $(12: 7+5)$ is, again, 1.4 times more than the token count produced by their counterparts in the CMC setting $(9: 5+4)$. Similarly, the token count for the word except produced by the participants in the face-to-face setting ( $8: 5+3)$ is 2.7 times more than the token count produced by their counterparts in the CMC setting (3: 1+2). Accordingly, we can infer that face-to-face storytelling led to more productive word gains and longer recall discourse in the delayed story recall test-a finding consistent with the immediate story recall test. 
Figure 2

Target words token count in the delayed recall test

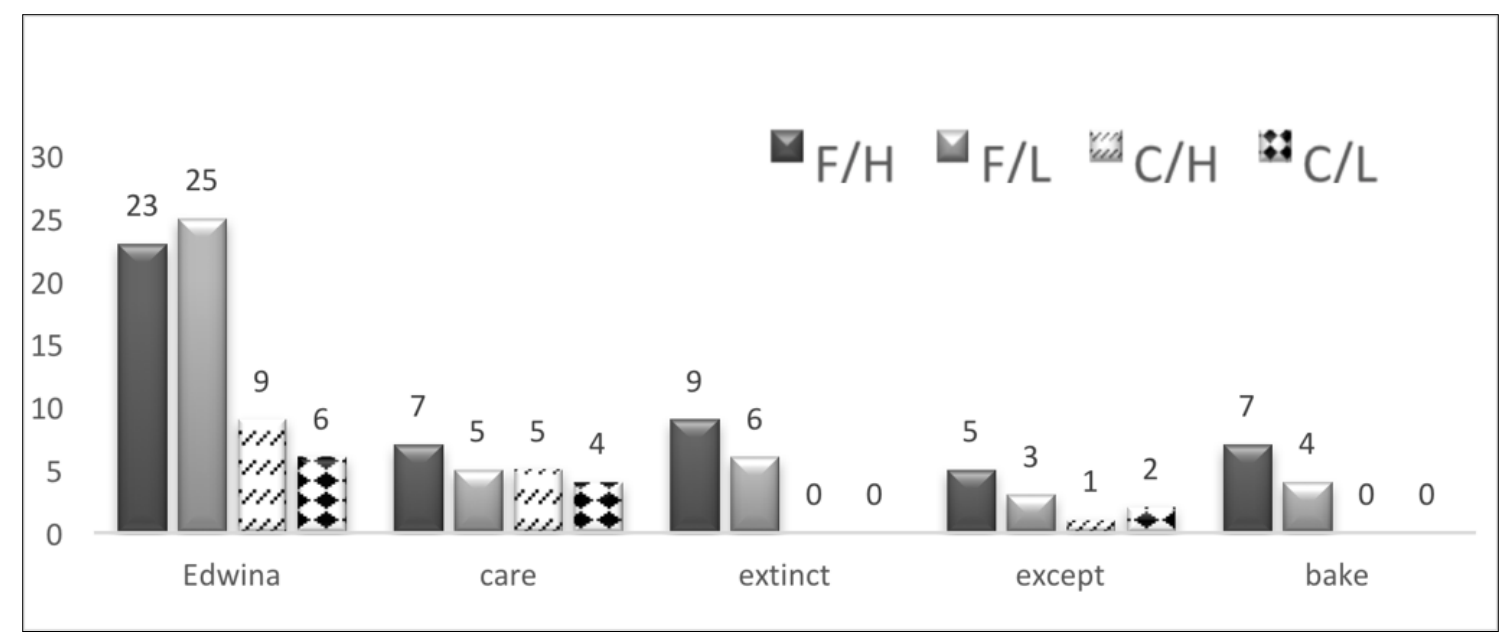

Notably, the two target words extinct and bake were only produced by the participants in the face-to-face storytelling setting: 17 and 15 times for the word extinct in the immediate and delayed story recall tests, respectively; 15 and 11 times for the word bake in the immediate and delayed story recall tests. The observation that these two words were only produced by the participants in the face-to-face setting is definitely not a coincidence, given the CMC and face-to-face groups' homogeneous linguistic profiles.

Additionally, while examining the productive word gains in the immediate and delayed story recall tests, we noticed one interesting finding: the involvement load difference only seemed to manifest in the face-to-face difference but not in the CMC setting; both the high and low-involvement participants in the CMC settings produced three target words. Specifically, while the high-involvement group optimized word production and retention in the face-to-face storytelling setting in the immediate and delayed recall tests, it did not seem to exert the same effect on the participants in the CMC setting. Rather, both of the results of the immediate and delayed story recall tests suggest that there was no difference in terms of the number of target words (type) produced in the CMC setting-a finding inconsistent with the receptive word gain.

To sum up, three important findings emerged from the present study. First, face-to-face and CMC storytelling contexts led to differential task involvement load with the participants in the face-to-face setting having higher involvement (compared to the participants in the CMC setting). This higher involvement seemed to lead to better receptive word gain, as seen in the participants' performance both in the immediate and delayed receptive vocabulary tests. In particular, the high-involvement participants in the face-to-face setting benefited the most and outperformed their low-involvement counterparts in receptive word gains. Second, face-to-face picture book storytelling also seemed to lead to better productive word gains and longer lexical recall units than their counterparts in the CMC setting, as seen in their performance on the immediate and delayed recall tests. Overall, the participants in the face-to-face setting outperformed their counterparts in the CMC setting. Notably, the high-involvement participants in the face-to-face setting were able to recall and retain significantly more target words and produce significantly longer lexical chunks than their low-involvement counterparts in both settings. Third, such a within-group difference between high and low-involvement participants was only manifest in the receptive word gain, but not the productive word gain, in the CMC setting.

\section{Discussion}

This study attempted to compare the effectiveness of EFL fifth graders' English vocabulary learning via videoconferencing or face-to-face storytelling sessions. In the current study, both groups of fifth graders in small groups received a storytelling session in either CMC and face-to-face contexts. The results are discussed according to the research questions. 


\section{What is the relative efficacy of videoconference and face-to-face storytelling in terms of their potency to promote $\mathrm{L} 2$ word acquisition?}

This study addressed whether the use of technology (in this case, conducting picture book sessions through CMC and the internet) leads to greater word gains compared to traditional face-to-face picture book storytelling. As noted earlier, every effort was made to ensure that the manner by which the picture book storytelling session was conducted was similar in the CMC and face-to-face settings; furthermore, the participants were highly comparable in terms of their overall linguistic profiles and speaking proficiency. In this regard, the major differences between the two settings of students were mainly in the settings in which setting the picture book storytelling was conducted and the differential degrees of (cognitive) involvement load invoked by these two settings. It is interesting to see that these differences had the potential to lead to differential (receptive and productive) word gains, with the face-to-face setting being the optimal one.

Specifically, both the CMC and face-to-face picture book storytelling allowed the L2 learners in this study to acquire receptive and productive knowledge of unknown L2 words, although the former seemed to be the more desirable setting to leverage the participants' receptive and productive word gains. I also seems that these gains were better retained in the face-to-face setting than in the CMC setting-a finding captured in Tables 4 and 5 . As will be discussed below (vis-à-vis the second research question), a higher involvement load seems to be the key to the success in the face-to-face picture book storytelling session. However, it is important to note that this study does not discount the potential benefits of storytelling via videoconference since the present study examined only one domain of language learning (vocabulary) and one style (L2 only) of storytelling. The advantage of the face-to-face picture book storytelling session is essentially based on one-shot cross-sectional data. Given more time and observation, the niche where CMC storytelling stands out may surface.

\section{How does the learners' involvement, as assessed by their states of need, search, and evaluation, affect the relative efficacy of videoconferencing and face-to-face storytelling in promoting L2 word acquisition?}

The task involvement in the face-to-face storytelling setting was higher than that of the CMC setting, which led to better receptive and productive word gains. Importantly, this higher involvement load also seemed to result in longer discourse. The higher involvement load in the face-to-face picture book storytelling setting can probably be attributed to learners' attention allocation, which echoes Kim's (2014) claims that in a CMC setting, the learners' attention allocation could be qualitatively different from a face-to-face setting. In the present case, namely, all attentional targets in the face-to-face picture book storytelling session were largely the product and direct reflection of their personal free will and decision, which led to higher involvement.

It is important to note that although higher involvement contributed to greater receptive and productive word gains in the face-to-face setting, such a trend was not sufficiently manifest in the productive vocabulary gains of the participants in the CMC setting. Notwithstanding, the observation that the involvement load difference (high vs. low) in the CMC setting did not seem to manifest in the productive word gain does not necessarily disconfirm the role of involvement in promoting productive vocabulary knowledge. It is possible that unlike the instructor in the face-to-face setting who was visible and hence able to provide detailed, clear articulatory cues (e.g., facial expressions, lip movements) that are crucial for productive word gains at all times, the instructor using videoconferencing was not able to provide such constant cues due to the constraints of videoconferencing storytelling via Skype (a constant close-up shot of the instructor's face is not possible). Such a constraint probably dampened the efficacy of the CMC participants' productive word gains. Furthermore, productive vocabulary knowledge takes a longer time to acquire-especially when learners do not have constant access to the teachers' facial articulatory cues at all times in the CMC setting-and this is probably why the effect of involvement load only manifested in the CMC participants' receptive, but not the productive, word gains. Accordingly, based on the findings of this study, we can infer that a higher involvement load generally plays a prominent role in aiding fifth grade EFL leaners' acquisition of novel English words.

The results of this study confirm that, when it comes to using a picture book as a medium for promoting L2 vocabulary learning, face-to-face storytelling is much more effective than the CMC option because face-to-face storytelling, in which the interaction between the teacher and students are authentic and intense and students can refer to the printed story books whenever they need, makes young learners more attentive and engaged in the process of storytelling. Meanwhile, the participants in the CMC group were easily distracted by the 
technology, which echoes Yu's findings (2018) that participants' learning is easily interfered with when multimedia effects were present, and this is a major concern that could hinder such a practice with young language learners. Accordingly, the findings of the study corroborate existing literature that storytelling facilitates vocabulary acquisition especially for young learners and further consolidates that intense involvement in storytelling sessions is needed for word acquisition (Chung, 2012; Lee, 2005; Lugo-Neris, Jackson, \& Goldstein, 2010),

In sum, instructors should seek various activities to conduct authentic and intensive interactions to enhance learners' involvement during picture book storytelling for optimal vocabulary learning outcomes.

\section{Conclusion}

A few limitations should be addressed for the current study. First, the study employed a small-scale sample with participants of the same grade level and similar language proficiency profile. It can, therefore, be recommended to further the study with larger and more diverse samples of participants utilizing statistical tools to establish the efficacy of face-to-face and CMC picture book storytelling in multi-level classes. Second, the study utilized a small number of target words, which is aligned with the fifth graders studying habits and pace prescribed in their regular textbooks. This design posed difficulties in utilizing advanced statistical tools to examine its statistical impact. Third, the study utilized an L2 as the only instructional language, which might pose potential challenges for comprehension and word acquisition. Additionally, vocabulary learning is a complex process. The ILH as a framework may overlook factors such as learners' interest and self-efficacy, which can be explored in future studies. Moreover, although reading comprehension is beyond the scope of this paper, attempts to investigate which storytelling strategies facilitate learners' comprehension will be useful to provide insight into the effects of storytelling with young EFL learners. Above all, a statistical significance test would be one of the major instruments for future studies. The reason for not adopting independent/paired $t$-tests in this study was due to the small number of words (six target words). For advanced studies in which more than one story book with larger amounts of words, sentence patterns, and reading comprehension sessions are selected as experimental instruction, appropriate statistical tools should be adopted.

\section{References}

Acar, A. (2007). Teaching languages from a distance through multipoint videoconferencing. Foreign Language Annals, 40(2), 311-319.

Akiyama, Y. (2019). Using Skype to focus on form in Japanese telecollaboration: Lexical categories as a new task variable. In Computer-Assisted language learning: Concepts, methodologies, tools, and applications (pp. 617647). IGI Global.

Anderson, T., \& Rourke, L. (2005). Videoconferencing in kindergarten-to-grade 12 settings: A review of the literature. Alberta Education.

Bower, J., \& Kawaguchi, S. (2011). Negotiation of meaning and corrective feedback in Japanese / English eTandem. Language Learning \& Technology, 15, 41-71.

Chen, J. J., \& Yang, S. C. (2014). Fostering foreign language learning through technology-enhanced intercultural projects. Language Learning \& Technology, 18(1), 57-75.

Chung, S. F. (2012). Based vocabulary instruction for English language learners. The Reading Matrix, 12(2), 105120.

Cuestas, A. (2013). Using Skype in a primary class: A case study. Bellaterra Journal of Teaching \& Learning Language \& Literature, 6(2), 49-68.

Fahy, P. J. (2007). The occurrence and character of stories and storytelling in a computer conference. Distance Education, 28(1), 45-63.

Han, Z.H., \& Chen, C-L. (2010). Repeated-reading-based instructional strategy and vocabulary acquisition: A case study of a heritage speaker of Chinese. Reading in a Foreign Language, 22(2), 242-262.

$\mathrm{Hu}, \mathrm{H}$. M., \& Nassaji, H. (2016). Effective vocabulary learning tasks: Involvement load hypothesis versus technique feature analysis. System, 56, 28-39. 
Hulstijn, J. H., \& Laufer, B. (2001). Some empirical evidence for the involvement load hypothesis in vocabulary acquisition. Language Learning, 51(3), 539-558.

Kim, H. Y. (2014). Learning opportunities in synchronous computer-mediated communication and face-to-face interaction. Computer Assisted Language Learning, 27(1), 26-43.

Kirsch, C. (2016). Using storytelling to teach vocabulary in language lessons: Does it work? The Language Learning Journal, 44(1), 33-51. https://doi.org/10.1080/09571736.2012.733404

Kitade, K. (2000). L2 learners' discourse and SLA theories in CMC: Collaborative interaction in internet chat. Computer Assisted Language Learning, 13(2), 143-166.

Laufer, B., \& Hulstijn, J. (2001). Incidental vocabulary acquisition in a second language: The construct of taskinduced involvement. Applied Linguistics, 22(1), 1-26.

Lee, L. (2002). Synchronous online exchange: A study of modification devices on non-native discourse. System, 30(3), 275-288.

Lee, S. Y. (2005). The robustness of extensive reading: Evidence from two studies. The International Journal of Foreign Language Teaching, 1(3), 13-19.

Lim, B. J., \& Pyun, D. O. (2019). Korean foreign language learning: Videoconferencing with native speakers. In Computer-Assisted language learning: Concepts, methodologies, tools, and applications (pp. 1123-1146). IGI Global.

Lowenthal, P.R., \& Dunlap, J.C. (2010). From pixel on a screen to real person in your students' lives: Establishing presence using digital storytelling. Internet and Higher Education, 13, 70-72.

Lugo-Neris, M. J., Jackson, C. W., \& Goldstein, H. (2010). Facilitating vocabulary acquisition of young English language learners. Language, Speech, and Hearing Services in Schools, 41(3), 314-327.

Malin, G. (2010). Is it still considered reading? Using digital video storytelling to engage adolescent readers. The clearing house, 83(4), 121-125.

Morgan, H. (2013). Technology in the classroom: Using Skype for exciting projects. Childhood Education, 89(3), 197-199.

Nation, P., \& Coady, J. (1988). Vocabulary and reading. In R. Carter \& M. McCarthy (Eds.), Vocabulary and language teaching (pp. 97-110). Longman.

Ockert, D. (2015). Increases in Japanese EFL Learners' Motivation, International Posture, and Interest in Foreign Language Activities after Skype Exchanges. Digital Culture \& Education, 7(2), 206-226.

Rassaei, E. (2017). Video chat vs. face-to-face recasts, learners' interpretations and L2 development: A case of Persian EFL learners. Computer Assisted Language Learning, 30(1-2), 133-148.

Terhune, N. M. (2016). Language learning going global: Linking teachers and learners via commercial Skypebased CMC. Computer Assisted Language Learning, 29(6), 1071-1089.

Tsukamoto, M., Nuspliger, B., \& Senzaki, Y. (2009). Using Skype copyright to connect a classroom to the world: Providing students an authentic language experience within the classroom. In CamTESOL conference on English language teaching: Selected papers (vol. 5, pp. 162-168). TESOL

Willems, M. (2006). Edwina: The dinosaur who didn't know she was extinct. Hyperion Books for Children.

Yen, Y. C., Hou, H. T., \& Chang, K. E. (2015). Applying role-playing strategy to enhance learners' writing and speaking skills in EFL courses using Facebook and Skype as learning tools: A case study in Taiwan. Computer Assisted Language Learning, 28(5), 383-406. https://doi.org/10.1080/09588221.2013.839568

Yeung, S. S., Ng, M., King, R. B., Yeung, S. S., NG, M. L., \& Ronnel, B. (2016). English vocabulary instruction through storybook reading for Chinese EFL kindergarteners: Comparing rich, embedded, and incidental approaches. The Asian EFL Journal Quarterly, 18(2), 89-112.

Zou, D. (2017). Vocabulary acquisition through cloze exercises, sentence-writing and composition-writing: Extending the evaluation component of the involvement load hypothesis. Language Teaching Research, 21(1), $54-75$. 